\title{
Social class and preventive health behaviour: a British example
}

\author{
Roisin Pill, T J Peters, M R Robling
}

\begin{abstract}
Study objective - To test the relationship between social class and preventive health behaviour in a British national sample and identify which set of more specific socioeconomic factors best "explained" any observed relationship(s).

Design - Secondary analysis from a national cross sectional survey of the health attitudes and health behaviour of men and women aged 18 years and over living in private households in England, Scotland, and Wales. A selection of addresses was made randomly from the electoral register using a three stage design, and then one individual in each household was sampled. A total of 12254 addresses yielded interviews with 9003 individuals, a response rate of $73.5 \%$. Compared with the census population, the single and divorced/separated are slightly under-represented but otherwise sources of bias are small.

Participants - The subset selected was 1671 women and 1026 men aged between 20-45 years with at least one child under 17 living at home.
\end{abstract}

Main results - Social class was strongly associated with the health practices index (HPI, used as a measure of health behaviour) both for women and men $(p<0.001)$. The set of factors identified for both sexes as having an impact on this relationship were education, tenure, residential overcrowding index, and salience of lifestyle. In addition, their partner's employment status and household income were relevant for women only. These groups of factors did not totally explain the observed relationship but the proportion of variance in HPI attributable to social class was considerably reduced.

Conclusions - Descriptions of the association between social class and health behaviour(s) are of little use to those wishing to mount more effective interventions in health promotion. Multivariable analysis can indicate which specific factors account for much of the social class effect on health behaviour and thereby assist better understanding and targeting of resources.

( $\mathcal{F}$ Epidemiol Community Health 1995;49:28-32)

In the continuing debate about the evidence for the widening of the gap between social groups over time, ${ }^{1-4}$ two concepts recur in the published reports - namely, class and pre- ventive behaviour. There is a wealth of evidence linking occupational class to the standard health indicators in a variety of contexts but there is less agreement about how these findings are to be interpreted. In particular, it is questioned whether they are valid in the light of problems surrounding the operational definitions and measurement of occupational class. In Britain this has generated an acrimonious debate centred on the Registrar General's social class classification, particularly when assessing trends in inequalities in mortality rates.

Despite the criticism, however, the Registrar General's classification continues to be used: in Carr-Hill's words, "the main reason it has survived so long is that, empirically, it works it does discriminate life chances and, in particular, death rates". ${ }^{5}$ Paradoxically, its undoubted success as a discriminator rests on the generality of its meaning. Thus, when researchers attempt to go beyond simple description to explore the possible causes for the observed relationships they are confronted by a bewildering array of dimensions of social position and experience associated with occupation, all of which may or may not be relevant.

The focus of this paper, however, is not to rehearse again the well known problems surrounding the use of the Registrar General's social class but to explore which aspects of the complexity of factors subsumed under that broad description are associated with preventive behaviour.

It is often postulated, that one reason for the increasing gap between the social classes in many of the standard health indicators ${ }^{67}$ is the difference in the way individuals from various social groups chose to lead their lives, particularly the behaviour and voluntary lifestyles they adopt.

This cultural/behavioural explanation for the often observed association between health and low socioeconomic status holds obvious attractions for policy makers and health educators. This is reflected in the emphasis on individual responsibility and prevention seen in official publications since the 1970 s, and culminating most recently in the specifications laid down in the new employment contract for general practitioners. The evidence for the cultural/behavioural explanation rests on the wide range of studies that have shown an association between more positive health behaviour (however defined) and higher socioeconomic status (SES) in Britain and north America ${ }^{8-13}$ However, less attention has been paid to producing an adequate explanation for these findings. 
As noted above, social class is, of course, merely a summary descriptive measure, not an explanation. It serves as a convenient indicator of differences in income, education, access to resources, attitudes, and other factors that may influence behaviour. The observed relationships may be due mainly to one or to a cluster of such factors and indeed their relative importance may well vary depending on the specific health behaviour under consideration.

When the three indices (income, education, and occupation) commonly used in the establishment of SES are compared for their power to predict health behaviour and differences are evident, education was usually found to be the most reliable correlate. ${ }^{8}$ In an attempt to investigate the possible mediators of the relationships between SES and health behaviours in a Canadian setting, Coburn and Pope ${ }^{9}$ developed six measures related to a number of the explanatory hypotheses that had been put forward. However, no single measure accounted for the relationships with the three forms of preventive health behaviour they used (use of preventive medical and dental services and polio vaccination) and together the six factors accounted for approximately one half of the common variance between SES and a combined index of the three behaviours studied.

To date, most research on British samples has been largely descriptive, confining itself to documenting the relationship between some behaviour/risk factor and social class rather than investigating the potential importance of its component factors. Consequently, this paper seeks to address these issues as part of a secondary analysis of a subset of the health and lifestyles survey data, the largest British survey to date on health beliefs and attitudes and health-related behaviour. ${ }^{14}$ The current project was designed to test hypotheses and findings derived from local studies of mothers with dependent children on similar samples drawn from a national data base. ${ }^{15} 16$ Access to this very large data bank also permits a composite index of health behaviour, developed and validated in the USA, to be replicated for the first

Table 1 Variables considered as possible confounders of any relationship between social class and behaviour

\begin{tabular}{ll}
\hline Level of disability & $\begin{array}{l}\text { Those with no physical disability } v \text { those with any } \\
\text { degree of disability }\end{array}$ \\
All those with some educational/vocational \\
qualifications $v$ those with no formal qualifications \\
Living in privately owned property $v$ rented \\
accommodation \\
Tenure & $\begin{array}{l}\text { Total household income less than } £ 230 \text { per month; } \\
\text { Employed full time/employed part time, not in paid }\end{array}$ \\
Income & employment \\
Work status (partner) & Employed full time/employed part time, not in paid \\
employment & 20-29/30-39/40-45 y \\
Work status (self) & None/one/two or more \\
Age & One/two/three or more \\
No of children under 5 & Total number including respondent \\
No of children under 17 & bedrooms $(<1 \cdot 0 ; 1 \cdot 0-1 \cdot 49 ; 1 \cdot 5+)$ \\
No in household & Married $v$ other \\
Index of residential overcrowding & Some lack of support (score, $<21 v$ no lack of support \\
Marital status & $>21)$ \\
Perceived social support index & High score $(10+) v$ low score $(0-9)$ \\
Social contact index & Those attending place of worship within last 2 weeks $v$ \\
Religious attendance & others \\
Sigh/medium/low score $(3,4 / 2 / 0,1)$
\end{tabular}

time on a national sample in Britain. The aims are then:

(1) To examine the relationship between a general index of health practices and social class and to test whether the same steep social class gradient reported in the literature for health status (however measured) is also found for this measure of preventive health behaviour;

(2) To explore what socioeconomic characteristics best "explain" any observed relationships with social class.

\section{Methods}

\section{THE SAMPLE}

The sample for analysis was drawn from the health and lifestyle survey carried out in 1984-85 of 9003 men and women aged 18 years and over living in private households in England, Wales, and Scotland. ${ }^{14}$ The subsample used in the present study consisted of 1671 women and 1026 men aged between 20 and 45 years with at least one child under 17 living at home.

\section{METHOD OF ANALYSIS}

Analyses were carried out separately for women and men and were performed using the analysis of variance procedure (ANOVA) of the SPSS$X$ package. ${ }^{17}$ Firstly, the relationship between social class and the measure of health behaviour, health practices index (HPI), was tested by a one way analysis of variance. The objective was to compare the mean of the HPI score across the social classes, the statistical significance of differences between means being represented by the standard F-ratio statistic.

The next step was to carry out a two way analysis of variance procedure by including each of a number of factors in turn with social class, the outcome variable again being the HPI score. Those variables which produced an appreciable decrease in the F-ratio for social class (and therefore seemed to be confounding factors in the relationship between social class and the HPI score) were then identified.

The third step was to model this set of variables together, alongside social class, in a multi-way analysis of variance. In this final "fully adjusted" model, the F-ratio and the associated $R^{2}$ value for social class represent respectively the independent statistical significance of social class and how much the variance in the HPI score across the social classes was not attributable to the other factors. The strength of the "adjusted" relationship between social class and HPI was also assessed by considering the adjusted means from the multivariable model.

\section{MEASURES USED}

(1) Social class was defined using the Registrar General's classification of occupations. ${ }^{18}$ Given the numbers involved, social classes I and II were combined for the analyses, as were social classes IV and V.

(2) The variables considered as possible confounders of any relationship between social 


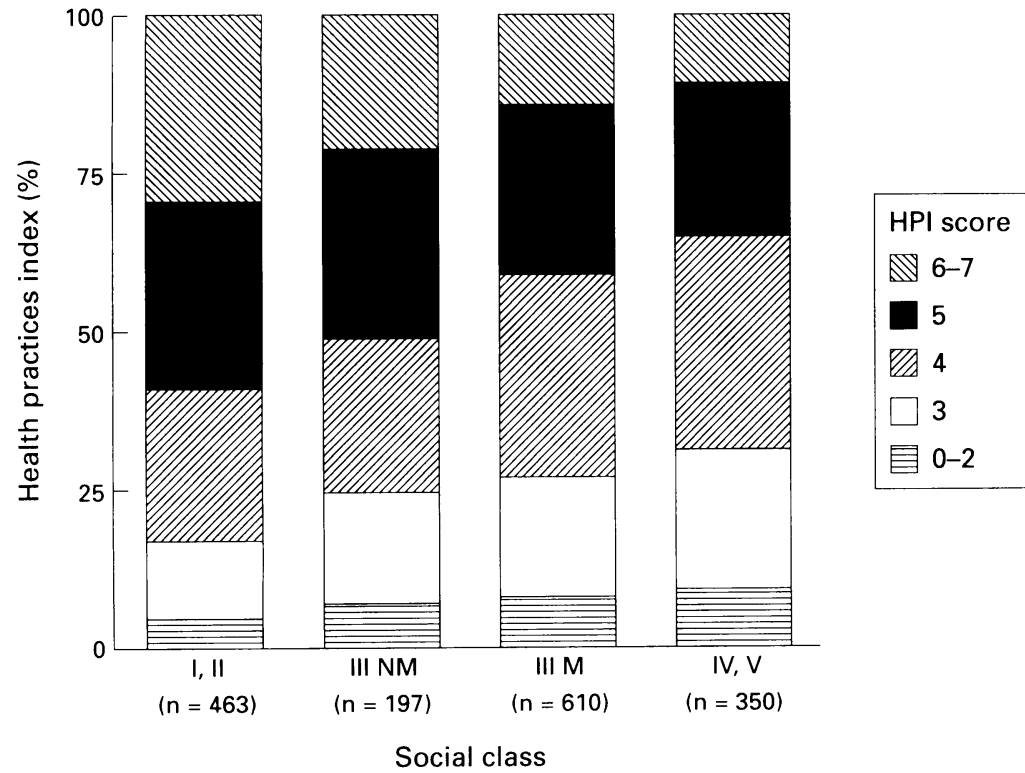

Figure 1. Distribution of health practices index (HPI) score across the social classes for 1620 women. and income, while work status is clearly linked to income. Marital status, age, and number of children should be relatively independent of occupation, education, and income and therefore one would not anticipate that they would act as confounding variables for any observed relationship between class and behaviour. Not withstanding this, as standard sociodemographic characteristics correlated with health behaviour, they were included for the first stage of the analysis.

The other variables need further explanation and can be conceptually grouped into measures of integration or participation and measures of belief and attitude. Measures of social support and integration (of which attendance at a place of worship is one) were included since they have been shown to be positively associated with health status and also to be associated with certain types of preventive health behaviour. Two measures of social integration are used: the social contact index contrasts those who have many social roles and social ties with those who seem to be isolated and is a more objective measure. Alternatively, subjective feeling about social support (the perceived social support index) may be considered to be a more important measure, whatever the actual family or social situation.

In so far as the different social class groups vary in their attitudes to health and preventive behaviour, then beliefs and attitudes may be mediating factors. The two indices of salience of lifestyle (SLI) used measure the extent to which the respondent recognises that lifestyle choices are relevant for future health status. ${ }^{19}$ A point is awarded for any mention of the relevance of individual behaviour in each reply to four, open ended questions; the scores therefore range from $0-4$. SLI (personal) is based on answers to questions about what the respondent him/herself did/thought, whereas SLI (general) is based on more general questions about sources of health, the "healthy person" and the issue of personal responsibility.

(3) The measure of health behaviour used here is based on the HPI developed by the Alameda County researchers who looked at the relationships of everyday health behaviour and health status with subsequent mortality and morbidity over a period of 20 years. ${ }^{20}$ Seven practices are summarised in a simple ordinal dimension; scores therefore range from 0-7 with higher values representing "better" health practices. In detail, a point is awarded for each of the following low risk practices: never having smoked; no/moderate use of alcohol; regular exercise; eating breakfast regularly; not snacking between meals; regularly sleeping $7-8$ hours each night; and being the correct weight for one's height. The choice of the practices to be included was based on work demonstrating that each practice was an important and independent predictor of subsequent mortality risk, with the cut-points also determined by the Alameda County analyses of the increase in mortality risk.

The advantages for our purposes, then, are that the HPI is a well validated summary measure and that it was possible to replicate it using the questions included in the health and lifestyle survey.

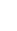

\section{Results}

(1) WOMEN

Of the 1671 women, both social class and HPI score were available for 1620 individuals. Amongst these, social class was found to be strongly associated with the HPI score with an F-ratio of 23.9 (degrees of freedom $=3,1616$; $\mathrm{p}<0.001)$. The proportion of variance in the score explained by social class was $4 \cdot 2 \%$. Women in social classes I and II had the highest mean score of $4 \cdot 72$, while progressively lower scores were recorded for those in categories IIINM, IIIM and IV, V $(4 \cdot 42,4 \cdot 21$, and $4 \cdot 07$ respectively). Figure 1 clearly shows the poorer performance of lower social class women on the HPI score.

Adjusting social class for each one of the other factors in turn typically resulted in a reduction in the F-value for social class, although it still remained highly significantly associated with the outcome variable throughout that seemed to have the greatest effect on the relationship between social class and HPI while controlling for work status actually increased the F-ratio for social class. Six factors were (table 2). Education and tenure were the factors 
Table 2 The effect of controlling for possible confounding factors on the association between social class and health practices index

\begin{tabular}{|c|c|c|}
\hline \multirow[t]{2}{*}{ Factor controlled for } & \multicolumn{2}{|c|}{$\begin{array}{l}\text { F-ratio for social class } \\
(p<0.001 \text { throughout })\end{array}$} \\
\hline & Women* & Ment \\
\hline Disability & $24 \cdot 5$ & $11 \cdot 5$ \\
\hline Education & $12 \cdot 6 \ddagger$ & $6 \cdot 8 \ddagger$ \\
\hline Tenure & $13 \cdot 0 \ddagger$ & $6 \cdot 5 \ddagger$ \\
\hline Income & $18 \cdot 1 \neq$ & $11 \cdot 4$ \\
\hline Work status (partner) & $19 \cdot 1 \neq$ & $11 \cdot 3$ \\
\hline Work status (self) & $25 \cdot 9^{\top}$ & $10 \cdot 5$ \\
\hline Age & $23 \cdot 4$ & $12 \cdot 5$ \\
\hline No of children under 5 & $24 \cdot 0$ & 11.5 \\
\hline No of children under 17 & $22 \cdot 4$ & $10 \cdot 8$ \\
\hline No in household & $22 \cdot 3$ & $10 \cdot 6$ \\
\hline Crowding index & $19 \cdot 5 \ddagger$ & $8.9 \ddagger$ \\
\hline Marital status & $22 \cdot 2$ & $11 \cdot 3$ \\
\hline Perceived social support index & 21.9 & $10 \cdot 4$ \\
\hline Social contact index & $24 \cdot 4$ & $11 \cdot 1$ \\
\hline Religious attendance & $20 \cdot 8$ & $10 \cdot \hat{1}$ \\
\hline Salience of lifestyle (personal) & $18 \cdot 4 \ddagger$ & $8 \cdot 6 \ddagger$ \\
\hline Salience of lifestyle (general) & 21.5 & $8 \cdot 7 \ddagger$ \\
\hline
\end{tabular}

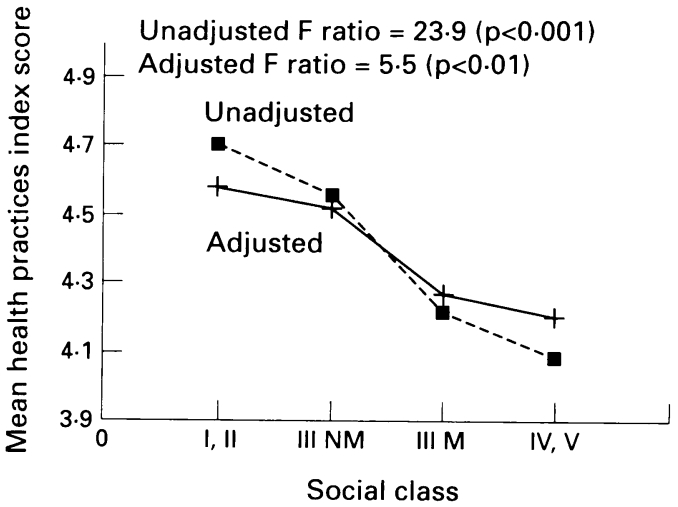

Figure 2. Mean health practices index across the social class groups for 1620 women both unadjusted and adjusted for six potential confounding factors - education, housing tenure, income, work status (partner), salience of lifestyle (personal), crowding.

therefore chosen to model further with social class, as indicated in table 2. Adjusting for all the possible confounders together resulted in a reduction in the F-ratio for social class from 23.9 to $5 \cdot 5$. This was, however, still significant
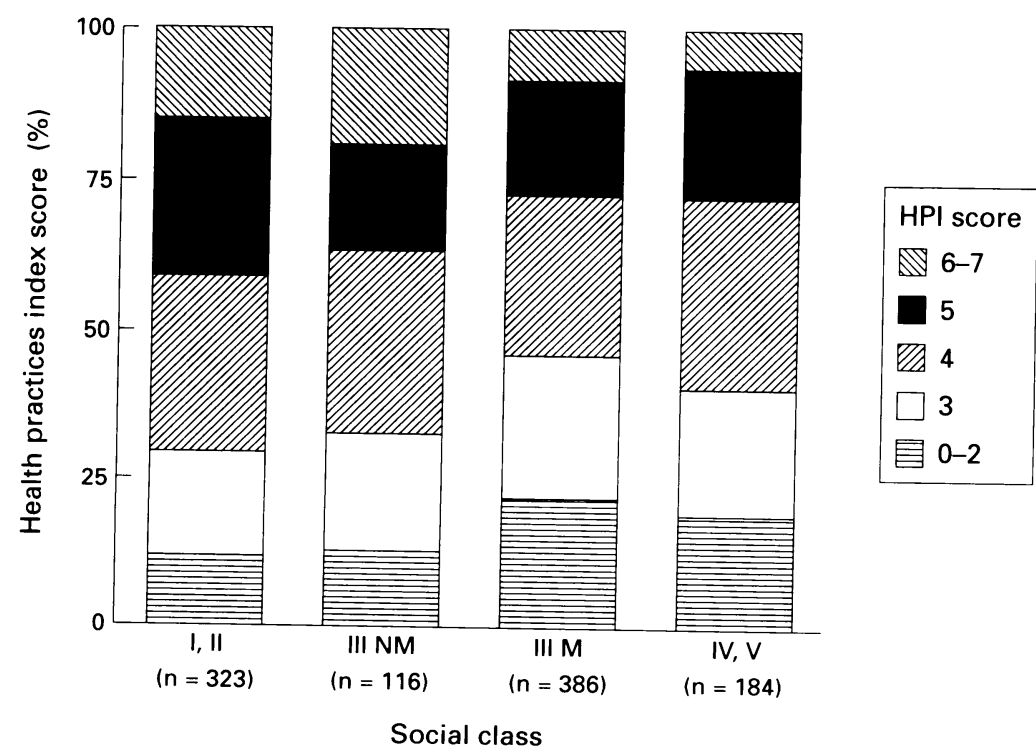

Figure 3. Distribution of health practices index (HPI) score across the social classes for 1009 men. at the $1 \%$ level and although the gradient in HPI scores across the social classes was reduced by this adjustment, it is still apparent (figure 2). However, the proportion of variance in the score now explained by social class, having adjusted for the other six factors, fell from $4.2 \%$ to $1 \cdot 3 \%$. The adjusted means (and $95 \%$ confidence intervals (CI)) for the four groups shown in figure 2 were respectively: $4.58(4.45$, $4 \cdot 71) ; 4 \cdot 56(4 \cdot 34,4 \cdot 78) ; 4 \cdot 22(4 \cdot 11,4 \cdot 33)$; and $4.09(3.94,4 \cdot 24)$

Women in the higher social classes still perform better on the HPI than those in the lower social class groups. The relative contribution of each of the confounding factors within the multiway model is difficult to assess and depends in no small part on the order that they are introduced into the model. Nevertheless, the variability in HPI scores across the social class groups cannot be wholly explained by the presence of this set of other factors.

\section{(2) MEN}

For the 1009 out of 1026 men for whom both variables were available, social class was found to be highly associated with HPI $(F=11 \cdot 3$; d.f. $=3,1005 ; \mathrm{p}<0 \cdot 001)$. Rather than the steady trend observed for the women, the difference across the classes for the men was such that those in the non-manual classes tended to perform more low risk health practices than the men in the two manual groups (figs 3 and 4). The adjusted mean (and 95\% CI) for the four groups shown in figure 4 were respectively: $3.94(3.79,4.09) ; 4.00(3.76,4 \cdot 24) ; 3.68$ (3.55, $3 \cdot 81)$; and $3 \cdot 91(3 \cdot 72,4 \cdot 10)$.

As shown in table 2, individually, none of the 17 factors reduced the statistical significance of social class below the $0 \cdot 1 \%$ level, although five did have a noticeable impact on the F-value. Adjusting for all these five simultaneously, however, still left the relationship between social class and HPI significant at the 5\% level (fig 4). The proportion of variance explained by social class, though, fell from $3 \cdot 3 \%$ to $0 \cdot 9 \%$. In addition, the pattern of means after adjustment for the five factors is such that the only apparent difference is a lower value amongst the social class IIIM men (fig 4).

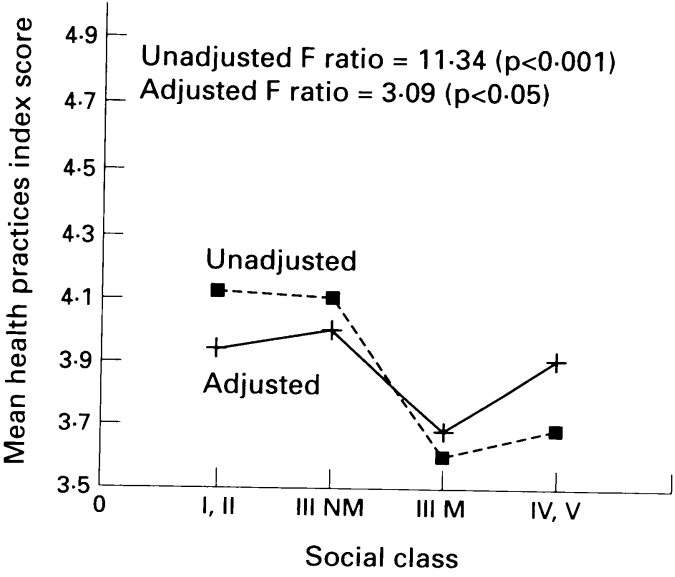

Figure 4. Mean health practices index score across social class groups for 1009 men both unadjusted and adjusted for five potential confounding factors - education, tenure, salience of lifestyle (personal), salience of lifestyle (general), crowding. 


\section{Discussion}

The first aim was to test whether the widely documented positive relationship between social class in Britain and health status (however measured) had a parallel in the relationship between social class and preventive health behaviour. Using the HPI, an association between social class and fewer risky health behaviours was demonstrated most convincingly for women while the picture was less clear for men. For the latter, instead of the expected trend a dichotomy emerged, with men in non-manual occupations performing more low risk behaviours than their peers in manual jobs. Overall, the amount of variance in the HPI score explained by social class was within the $1-10 \%$ range found in previous studies. In the present study the proportion of variance explained was slightly greater for women than for men.

The second aim was to explore which set of the socioeconomic factors investigated as possible mediators best "explained" the highly significant observed relationship between social class and behaviour. Most of the factors identified were very similar for the two sexes: education, tenure, level of crowding, and the measure of recognition that lifestyle influenced health status (SLI). However, there were interesting exceptions since the work status of the partner and household income were relevant factors for women but not for men. Allowing for these sets of confounding variables did not entirely remove the statistical significance of social class, a result consistent with previous findings. ${ }^{9}$ However, the differences between the means were reduced considerably, as were the proportions of variance in HPI explained by social class. In terms of the proportional reduction in $\mathrm{R}^{2}$ values the change was about $70 \%$ for both sexes.

For both sexes the set of factors identified as having some impact on the social class relationship with health behaviour are as would be expected from earlier work. What is perhaps more interesting in the present study is what was not identified as relevant; for example, the measures of social support had no such impact for either sex and neither did household income or partner's employment status for the men.

Nevertheless, having more than the minimal level of education, recognising the link between healthy lifestyle and future health, buying one's own house/flat and not living in cramped conditions were all associated with performing fewer risky health behaviours among both men and women. Thus, education, health attitudes, and immediate social circumstances seem to be aspects of social class that account for much of its observed association with health behaviour.

Determining exactly which of these confounding factors has the dominant effect in the multiway model would require a different analysis and was not the purpose of the present investigation. In our view, the next step should be to investigate the detailed relationships of the various factors with HPI for each separate sex and social class group. An example of this type of analysis has been published elsewhere. ${ }^{21}$ Such investigations will throw a much clearer light on the complex web of factors underlying simple descriptive statements on the relationship of social class and preventive health behaviour and assist those concerned with health promotion to target specific groups more effectively. On this point, it is encouraging that the specific factors identified here (education, health attitudes, and immediate social circumstances) are potentially more susceptible to modification. It suggests that interventions need to include a traditional health education component, and a more positive emphasis on individual empowerment. This would be aimed firstly at the promotion of more positive attitudes towards one's own health (and, development of the appropriate skills to translate these into action) and secondly, at the development of an awareness of the possibility of joint action to alter the immediate environment.

The work on which this paper is based was financed by a grant from the Health Promotion Research Trust, we are grateful to their colleagues in the Departments of General Practice and Medical Computing and Statistics, UWCM for their support.

1 Wilkinson RG, ed. Class and Health London: Tavistock Publications, 1986.

2 Pamulk ER. Social class inequality in mortality from 1921 to 1972 in England and Wales. Population studies 1985; 39:17-3

3 Davey Smith G, Baetley $M$, Blane $D$. The Black report on socio-economic inequalities in health 10 years on. $B M \mathcal{F}$ 1990;301:373-7.

4 Davey Smith G, Egger M. Socio-economic differentials in wealth and health. BMF 1993;307:1085-6.

5 Carr-Hill R. The measurement of inequalities in health: Lessons from the British experience. Soc Sci Med 1990; 31:393-404.

6 Smith A, Jacobson B. The nation's health. London: King Edward's Hospital Fund, 1988.

7 Whitehead M. The health divide, In: Townsend P, Davidson $\mathbf{M}$, Whitehead $\mathbf{M}$, eds. Inequalities in health. London: Penguin Books, 1988 .

8 Norman RMG. The nature and correlates of health behaviour. Ottawa: Health Promotion Directorate, Health and Welfare, Canada, 1986.

9 Coburn D, Pope CR. Socio-economic status and preventive health behaviour. $\mathcal{f}$ Health Soc Behav 1974;15:67-78.

10 Gottlieb MH, Green LW. Life events, social network, lifestyle and health: an analysis of the 1979 national survey of personal health practices and consequences. Healt Educ $Q$ 1984;11:91-105.

11 Steele JL, McBroom WH. Conceptual and empirical dimensions of health behaviour. $\mathcal{F}$ Health Soc Behav 1972 13:382-92.

12 Canada Health Survey. The health of Canadians. Ottawa: Ministry of Supply and Services, 1981.

13 Blaxter M. Health and lifestyles. London: Tavistock/Routledge, 1990.

14 Cox BD, Blaxter M, Buckle ALJ, et al. The health and lifestyle survey. Cambridge: Health Promotion Research Trust, 1987.

15 Pill R, Peters TJ, Robling MR. How important is health behaviour to the health of mothers of lower socio-ecobehaviour to the health of mothers of lower socio-ec
nomic status? F Public Health Med 1993;15:77-82.

16 Pill R, Peters TJ, Robling MR. Working class health beliefs and behaviours and their implications for health promotion in primary care. Report to the Health Promotion Research Trust. Cardiff: Department of General Practice, University of Wales College of Medicine, 1990.

17 SPSS-X Users guide. 3rd ed. Chicago: SPSS Inc, 1988.

8 Registrar General. Classification of occupations. London HMSO, 1970 .

19 Pill R, Stott NCH. Development of a measure of potential health behaviour: a salience of lifestyle index. Soc Sci Med 1987;24:125-34

20 Berkman LF, Breslow L. Health and ways of living: the Alameda County study. Oxford: Oxford University Press, 1983.

21 Pill R, Peters TJ, Robling MR. Factors associated with health behaviour among mothers of lower socio-economic status: a British example. Soc Sci Med 1993;36:1137-44. 